\title{
ANDANÇAS COM ILANA BLAJ
}

\author{
István Jancsó \\ Depto. de História - FFLCH/USP
}

lana Blaj deixou uma saudade carregada da lembrança de emocionantes aventuras pedagógicas e intensas divergências historiográficas. Às primeiras guardo como ganhos do meu aprendizado, e a elas retornarei adiante. Quanto às divergências, permanece para sempre a memória do ritmo sereno do seu fluir, produto da compreensão de Ilana de uma verdade em desuso: ela sabia perfeitamente que, contrariamente ao que muita gente insiste em pensar, a crítica acadêmica jamais envolve a honra da família de quem quer que seja, sendo, se apropriadamente manejada, demonstração de respeito e, no limite, de generosa cumplicidade. Vem daí que, por tratar-se de pessoa de semelhante qualidade, é pura obrigação liquidar débito remanescente, tarefa a que tenho me dedicado desde que pontuamos questões a serem fraternalmente tiradas a limpo.

Vamos aos fatos. Em 1993, por ocasião do XVII Simpósio Nacional de História da ANPUH, participávamos de uma mesa para apresentar (eu) e debater (Ilana e Afonso Carlos Marques dos Santos) o que me parecia ser novo e útil aporte para a discussão da abrangência social da sedição de 1798 na Bahia . Naquela ocasião, achando temerária a rota de colisão com a historiografia canônica na qual eu forcejava, e tendo por insuficiente o novo aporte documental apresentado em reforço a

\footnotetext{
${ }^{1}$ István JANCSÓ. "Adendo à discussão da abrangência social da Inconfidência baiana de 1798” in Blaj. I. e Monteiro, J.M. História e Utopias. São Paulo, ANPUH, 1996.
} 
uma proposição - já velha de um quarto de século ${ }^{2}$ - postulando que gente da elite baiana estaria no centro daqueles eventos, Ilana lançou o desafio: "que outro tipo de material poderia ser trabalhado?" ", se o caminho da revisão passava, como eu afirmava, por novos aportes documentais recomendando a revisitação de um tema cujo trato, segundo manifestações recentes de historiadores de renome, já mal se justificava.

Ainda que sorte e perseverança tenham-me levado ao original do "Projeto Larcher", documento submetido à apreciação do Directoire em 1797, e mediante o qual o militar francês deu forma às tratativas revolucionárias de setores da elite baiana - com o que tenho por provada minha hipótese original quanto ao espectro social da conspiração, ponto central das nossas (de Ilana e minhas) divergências datadas de 1993, não me parece pertinente dar por quitada a dívida com a simples indicação de cota de documento ou de título de texto onde apresento a prova longamente esperada $^{4}$, pois assim fazendo, estarei fugindo do espírito da sua pergunta.

De fato, o "material" da pergunta, aquele a ser prioritariamente definido, tem caráter essencialmente teórico, pois é essa a natureza das operações que conferem significado ao nosso trato com o saber constituído, alicerce cuja consistência determina a escala de relevância dos problemas que pautamos, esses enigmas cuja chave estará sempre na documentação, para o bem (quando esta é encontrada), ou para o mal (quando ela nos escapa). As vicissitudes do meu encontro com o "Projeto Larcher" ilustram o que quero dizer.

Desde sempre, a curta estadia do oficial francês em Salvador despertou o interesse de cronistas e historiadores, a ponto de ter levado Kátia Mattoso à busca de traços do marujo em arquivos franceses, com o material por ela encontrado posto à

\footnotetext{
${ }^{2}$ Vide István JANCSÓ. Contradições, tensões, conflito - A Inconfidência baiana de 1798, Rio de Janeiro, 1975, minha tese de Livre Docência apresentada à UFF (mimeo).

${ }^{3}$ Ilana BLAJ. "Questões a respeito do movimento baiano de 1798" in Blaj, I. e Monteiro, J.M. História e Utopias. São Paulo, Anpuh, 1996, p.297

${ }^{4}$ Isso está em István JANCSÓ. "Bahia 1798 - a hipótese do auxílio francês ou a cor dos gatos" in Júnia FURTADO (org.). Diálogos Oceânicos. Belo Horizonte, Ed.UFMG (no prelo).
} 
disposição de Luís Henrique Dias Tavares . O que consta do "Dossiê Larcher", referido mas não divulgado pelo historiador baiano, pelo que tudo indica pouco acrescentou que fosse merecedor de especial destaque quanto aos aspectos diretamente políticos dos episódios dos quais Larcher participou em Salvador. Isso, porém, não significou que não permanecessem guardados outros papéis de enorme interesse (caso do Projeto Larcher), e que escaparam à atenção de quem por eles procurava ${ }^{6}$. E outros mais podem estar aí à espera de quem os consulte, já que o autor do "Projeto" dá notícia de uma mémoire que ele mesmo submeteu à apreciação do Diretório, e cujo conteúdo, se tornado acessível, poderia lançar luz sobre as pessoas envolvidas na articulação revolucionária que, caso tivesse sido bem sucedida, teria colocado a Capitania da Bahia sob protetorado da França revolucionária.

Se esta mémoire ainda existe, é coisa a ser esclarecida mediante retorno aos arquivos. Mas não é esse o ponto. O que pode merecer estatuto de respeitosa resposta à pergunta de Ilana, é o reconhecimento de que a localização do "Projeto" expõe uma das muitas faces do impasse do pesquisador quando a análise teórica defrontase, num dado momento, com a freqüente combinação do silêncio da documentação conhecida com a ausência daquela que, forçosamente, deveria ter existido. Situações como essa, para cuja resolução meu mestre Eduardo d'Oliveira França recomendava o bom uso do critério da verossimilhança, e para o que, navegando nas águas de Fernando Novais (de quem ninguém foi aprendiz impunemente), aprendi a não negociar com os conceitos, tornam obrigatório o respeito à linha que separa a hipótese consistentemente construída de uma demonstração apressada, valorizando a primeira e recusando a segunda, notória fonte de descaminhos.

E de resto, e até pelo fato de confiar mais na importância das dúvidas do que na das certezas (o que talvez explique porque dos resultados das pesquisas em que

\footnotetext{
${ }^{5}$ Luís Henrique Dias TAVARES. História da sedição intentada na Bahia em 1798 ("A conspiração dos Alfaiates”). São Paulo/Brasília, Pioneira/INL, 1975.

${ }^{6}$ A descoberta e divulgação do "Projeto Larcher" deve-se a Jeanine POTELET. "Projets d'expéditions et d’attaques sur les côtes du Brésil (1796-1800). Caravelle nº 54, 1990.
} 
tenho-me empenhado tendam a adquirir um sentido quase obrigatório de pergunta gerando pergunta), devo responder a Ilana, interlocutora sempre presente, que no fim das contas, cada vez acredito mais sermos nós mesmos - e as nossas circunstâncias - esse "material" a ser antes de tudo trabalhado, circunstâncias que, por nossa deliberada opção, organizam-se em torno da História na simultaneidade de sua dimensão de passado, presente e futuro.

Com isso, creio poder devolver esta divergência carinhosamente acalentada para o lugar que é verdadeiramente seu, um pequeno desvio em meio a uma trajetória intensamente partilhada naquele que foi o campo preferencial de nossas circunstâncias: o ensino da História com suas infinitas possibilidades, surpresas, desafios e responsabilidades.

Devo ao PET (Programa Especial de Treinamento), então ainda vinculado à $\mathrm{CAPES}^{7}$, a possibilidade de conhecer Ilana para além dos limites da sociabilidade acadêmica mais ou menos formal que caracteriza a maior parte das relações entre docentes-pesquisadores no Departamento de História, pois foi nesse âmbito que instauramos um espaço de trabalho e reflexão que, por mais de quatro anos, e com perfeita regularidade, debruçou-se sobre todas as dimensões do nosso ofício.

A título de recordação, vale a pena registrar que a instalação do Grupo PETHistória deu-se em meio às melhores expectativas. As regras do jogo eram claras e, por mais trabalhoso que fosse o atendimento das exigências institucionais (relatórios, programações, prestações de contas, etc), fazê-lo justificava-se pelo enorme ganho de qualidade que o Programa abria para a formação dos estudantes nele direta e indiretamente envolvidos. Comparativamente aos outros programas de tipo "iniciação científica”, o PET impunha o compromisso de integração dos envolvidos

\footnotetext{
${ }^{7}$ O PET era um programa da CAPES voltada para a graduação, configurando, em escala nacional, uma das iniciativas mais bem sucedidas nesse campo, conforme informam as várias avaliações levadas a cabo. Esse sucesso motivou o interesse das autoridades do Ministério da Educação pelo programa, interesse que resultou na sua implosão e, em meio ao caos instaurado, na sua transferência para a SESU daquele Ministério, já completamente desfigurado, em 1999.
} 
(estudantes e professores) no cotidiano do Departamento, local qualificado como de trabalho permanente, e não de mera passagem rumo às salas de aula. Isso não representou, em si mesmo, novidade para Ilana e para os outros colegas envolvidos no Programa, pois todos nós, cada qual à sua maneira, estávamos empenhados em práticas dessa natureza. Mas havia uma novidade aberta pelo PET: a dimensão coletiva que esta permanência poderia assumir.

Foi isso que mais agradou a Ilana. Ela percebeu que o PET era dotado de um potencial quase subversivo se deflagrado em ambientes tendentes à rotinização da vida universitária, essa patologia dissolvente tanto da tensão intelectual quanto da cívica, a primeira sendo condição da crítica, a segunda indispensável para conferir estatuto de espaço de liberdade à universidade pública, tensões sem as quais esta acaba reduzindo-se a pouco mais que indiferenciada repartição prestadora de serviços de discutível qualidade. De fato, a voluntária aceitação das normas que regiam ingresso e permanência no PET, porque somente poderiam ser honradas mediante trabalho consistente de alunos e professores numa perspectiva que via o aprendizado escolar como exercício de cidadania, trazia em si a indução de uma sinergia que inevitavelmente repercutiria, como de fato veio a ocorrer, sobre a relação dos envolvidos com o curso de História.

Ilana percebeu tudo isso com luminosa clareza e levou essas possibilidades ao seu limite máximo. Dado que o Grupo PET-História chegou a integrar 16 pessoas (doze bolsistas e quatro professores), configurando uma diversidade de interesses (teóricos, metodológicos, pedagógicos ou profissionalizantes) que não poderiam ser contemplados com a adoção de um único recorte temático, optou-se, para dar conta desta situação, por uma estratégia que conjugava duas abordagens, uma contemplando a dimensão prática do ofício, a outra envolvendo a dimensão teórica que lhe é inerente.

No tocante ao primeiro ponto, a idéia de fundo resumia-se a abrir espaços de treinamento na esfera dos fundamentos operacionais do fazer historiográfico, objetivando, com isso, que os estudantes adquirissem, pela prática, o domínio das operações básicas de coleta e organização de informações; que as exercitassem até 
adquirirem destreza no seu uso, e que conhecessem o instrumental conceitual necessário para superar uma perspectiva estritamente mecânica daquelas operações. Para fins práticos de treinamento, o Grupo deu andamento a três linhas de trabalho: uma atividade centrada na organização de conjuntos documentais; uma outra no trato da linha do tempo, e uma terceira estruturada com vistas à organização de documentação relativa à cultura material ${ }^{8}$. Essas atividades corriam em paralelo com a segunda das abordagem acima referidas, desdobrada em múltiplas atividades envolvendo formação teórica, esse inescapável fundamento do nosso ofício, o único capaz de dotar seu aprendiz do instrumental de orientação em meio às divergências interpretativas que perpassam o universo da historiografia, esse local da afanosa apropriação da erudição que distingue o historiador do contador de histórias. Confrontar os estudantes com a esfera da reflexão teórica trazia em si, portanto, dois objetivos, o mais importante dos quais era o de colocá-los em condições de, aliando a percepção da multiplicidade de interpretações correntes com o domínio de elementos da crítica, precaverem-se do risco de tomarem forma por conteúdo, retórica por elaboração teórica ou, muito simplesmente, gato por lebre. E entremeado com este, o outro objetivo era o de abrir-lhes a possibilidade de, pela prática, darem-se conta de que a coesão ao Grupo somente teria consistência se fossem respeitadas as divergências que tinham curso em seu interior, e que isso se desse sem prejuízo das convicções pessoais.

\footnotetext{
${ }^{8} \mathrm{O}$ primeiro desses projetos, denominado "Catálogo de fontes impressas sobre a História de São Paulo" era orientado por Ilana Blaj, e contava com a participação dos graduandos Marco Aurélio Fernandes Gaspar, Lucas Jannoni Soares, Luciano Alves Onça, Francisco Paulo Bucieri Jr e Eder Camargo, além da colaboração da Professora Ana Maria Camargo. Conforme consta do Relatório de março de 1998, o grupo já havia catalogado mediante transcrição para as respectivas fichas o constante das seguintes coleções: Documentos Históricos da Biblioteca Nacional do Rio de Janeiro; Revista do Arquivo Municipal de São Paulo, Revista do Instituto Histórico e Geográfico Brasileiro, Revista do Instituto Histórico e Geográfico de São Paulo e Anais da Biblioteca Nacional. Os outros projetos eram: "Catálogo bibliográfico e iconocráfico sobre engenhos de açúcar no período colonial", orientado pelos Professores Norberto L. Guarinello e Vera Lúcia do Amaral Ferlini, e "Cronologia de História do Brasil Monárquico (1808-1889)", orientado por István Jancsó (cf. Grupo PETHistória - 5 .Relatório Semestral de Atividades (Agosto de 1997-Março de 1998), p.15-18.
} 
Tudo isso deu-se de modo intenso, freqüentemente tenso como costuma ocorrer em meio ao aprendizado disso de lidar com divergências, mas sempre alegre e em geral muito produtivo. E hoje, olhando em perspectiva, ganha clareza algo que então apenas se intuía: o grande mérito do Grupo PET estava em ter sabido valorizar o que cada qual tinha de melhor a oferecer ou, quando isso não foi atingido, em tê-lo tentado. E chegando a esse ponto, é fácil compreender porque coube a Ilana o papel de ponto de equilíbrio do Grupo, e porque foi dela a capacidade de revelar, na prática, que tendíamos a aceitar, mesmo querendo recusá-la, a subordinação da qualidade das práticas educativas às formas ditadas pela ratio administrativa. $\mathrm{O}$ seu envolvimento com o PET, ao integrar sua extraordinária qualidade de professora no cotidiano do Programa, eliminou o risco sempre presente da inversão que toma formato administrativo por substância acadêmica (e vice-versa), com o que fica claro que não foi o Programa que abriu um espaço diferenciado de criação e experimentação de novas variantes na formação de graduandos de História para Ilana mas, pelo contrário, foi a sua ação que conferiu qualidade diferenciada ao que ocorria no âmbito do PET.

Mas não foi somente no espaço restrito do PET, que Ilana revelou-me o melhor caminho a ser trilhado. Quem por alguma vez se deteve para observar o que acontecia na sala de aula onde ela dava conta do seu curso de História do Brasil Colonial (fosse às três horas da tarde, ou trinta minutos faltando para a meia noite), não podia deixar de se maravilhar com o espetáculo de setenta ou mais estudantes, os olhos brilhantes de emoção diante da aventura intelectual que lhes era desvendada, acompanharem cada gesto e palavra de Ilana, simples e magnífica em meio à circunstância de sua eleição: a nobre arte de bem ensinar.

Lembro-me bem que, ao folhear um trabalho de estudante de primeiro semestre cuidadosamente anotado com sua letra regular, ter-me dado conta de estar diante da materialização necessariamente tranqüila da grandeza do nosso ofício, pois era isso que vinha documentado nas observações atentas, nas críticas precisas e nas sugestões pertinentes. Nas suas anotações, Ilana expunha, sem afetação, as regras básicas deste nosso ofício: integral respeito pelo aluno-interlocutor; capacidade de transformar entendimento equivocado em patamar de crescimento; rigor da crítica 
como cimento da confiança intelectual e, finalmente, a sadia cumplicidade resultante do partilhado encantamento com a História.

Eis alguns dos meus ganhos com as andanças que me foram dadas partilhar com Ilana, todos guardados com muito afeto. E toda vez que me vem à memória seu sorriso aberto em meio aos bons combates que era incapaz de recusar, ganha força minha certeza de que seu maior legado está na lembrança da sua cotidiana demonstração de que o verdadeiro objeto da História é a vida, esse privilégio por cuja qualidade cada qual, e todos, somos absolutamente responsáveis. 